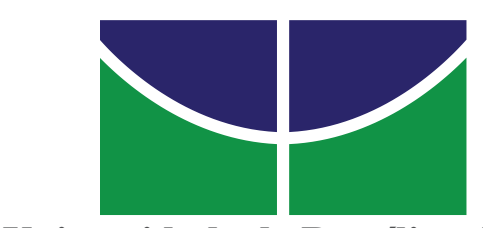

Universidade de Brasília - UnB

Faculdade de Economia, Administração, Contabilidade e Ciência da Informação e Documentação - FACE.

Programa de Pós-Graduação Administração - PPGA

JÚLIO JOSÉ DE ARAÚJO FILHO

A INFLUÊNCIA DAS IFES NA DECISÃO DO ORÇAMENTO NO CONGRESSO NACIONAL : O CASO DA UNIVERSIDADE DE BRASÍLIA (UnB) DE 2000 à 2009. 
JÚLIO JOSÉ DE ARAÚJO FILHO

A INFLUÊNCIA DAS IFES NA DECISÃO DO ORÇAMENTO NO

CONGRESSO NACIONAL : O CASO DA UNIVERSIDADE DE

BRASÍLIA (UnB) DE 2000 à 2009.

Monografia apresentada à Faculdade de Economia, Administração, Contabilidade e Ciência da Informação e Documentação (FACE) da Universidade de Brasília, como requisito parcial à obtenção do grau de Especialista em Gestão Universitária.

Orientadora: Prof. Dr. Moisés V. Balestro.

Brasília - DF

2010 


\title{
A INFLUÊNCIA DAS IFES NA DECISÃO DO ORÇAMENTO NO CONGRESSO NACIONAL : O CASO DA UNIVERSIDADE DE BRASÍLIA (UnB) DE 2000 à 2009.
}

\author{
JÚLIO JOSÉ DE ARAÚJO FILHO
}

\begin{abstract}
Monografia apresentada à Faculdade de Economia, Administração, Contabilidade e Ciência da Informação e Documentação - FACE da Universidade de Brasília, como requisito parcial à obtenção do grau de Especialista em Gestão Universitária.
\end{abstract}

Banca Examinadora

PROFESSOR DOUTOR MOISÉS V. BALESTRO

(ORIENTADOR).

$\overline{\text { PROFESSOR DOUTOR HENRIQUE CARLOS de O. de CASTRO }}$ (AVALIADOR). 
Lista de Abreviações e Siglas:

ANDES $=$ Sindicato Nacional dos Docentes das Instituições de Ensino Superior ANDIFES = Associação Nacional dos Dirigentes das Instituições Federais de Ensino Superior

Art. $=$ Artigo

Bancada de DF = Bancada de Deputados e Senadores do DF

$\mathrm{CD}=$ Câmara dos Deputados

$\mathrm{CEC}=$ Comissão de Educação e Cultura

$\mathrm{CF}=$ Constituição Federal

$\mathrm{CMO}=$ Comissão Mista de Orçamento e Planos

$\mathrm{CN}=$ Congresso Nacional

CT = Comissão de Ciência e Tecnologia

Dep. $=$ Deputado

FACE $=$ Faculdade de Administração Contabilidade e Economia

FASUBRA $=$ Federação dos Sindicatos dos Trabalhadores das Universidades Públicas

Brasileiras

IFES = Instituições Federais de Ensino Superior

MEC $=$ Ministério da Educação

PDI = Plano Diretor Institucional

$\mathrm{PL}=$ Projeto de Lei

RICD $=$ Regimento Interno da Câmara dos Deputados

RIDE $=$ Região Integrada de Desenvolvimento do Entorno

RISF $=$ Regimento Interno do Senado Federal

Sen. $=$ Senador

$\mathrm{SF}=$ Senado Federal

SGM = Secretaria Geral da Mesa da Câmara dos Deputados

SILEG $=$ Sistema de Informações Legislativas

UnB = Universidade de Brasília

UNE - União Nacional dos Estudantes 
Resumo

Este estudo tem como objetivo demonstrar como se dá a relação da Universidade de Brasília (UnB) com o Congresso Nacional $(\mathrm{CN})$, no âmbito das suas comissões de mérito, principalmente na Educação e Cultura, Ciência e Tecnologia e na Comissão Mista de Orçamento e Planos do Congresso Nacional. Vai ser estudada a atuação da UnB junto ao CN com vistas a compreender o mecanismo de elaboração, discussão e votação do orçamento, como a UnB define suas prioridades e as encaminham ao $\mathrm{CN}$, desde a inclusão e posterior liberação das emendas parlamentares. Essa participação tem demonstrado maior eficiência e um aperfeiçoamento na colaboração entre a UnB e os congressistas, principalmente a Bancada do DF, de forma a influenciar a mesma, na decisão, no uso e distribuição dos recursos orçamentários, para solucionar problemas da Educação Superior e avançar na expansão do Ensino Superior Público, para a população do DF e da RIDE, dentro de um processo de socialização no contexto democrático.

Nesse sentido, é importante compreender o contexto social e a história da UnB, suas propostas, e também, o seu projeto de expansão. Ao analisarmos a série histórica de 2000 à 2009, das emendas parlamentares, que se transformaram em recursos financeiros para UnB e compararmos os resultados dessa atuação, com as emendas da ANDIFES que também atua no $\mathrm{CN}$ representando o conjunto das IFES, ou com o grupo de universidades cujos Estados possuam bancadas similares, ou seja, com bancadas próximas à do DF, ou mesmo grupos de IFES cujas bancadas são maiores, constatamos que a UnB é uma instituição que se destaca nesse processo.

Nesse período, de 2000 à 2009, com a crescente massificação do ensino superior, exigência da sociedade - Campi grandiosos e manutenção cara, interiorização dos cursos e ao mesmo tempo a diminuição de recursos financeiros, materiais e humanos, fizeram com que a competição entre as IFES por recursos, criassem a necessidade de fomentar a influência positiva no Congresso Nacional, sem atuar como um fator degenerativo entre as instituições e o governo democrático, para que UnB possa atender a comunidade do DF e região. 
SUMÁRIO

INTRODUÇÃO 4

Capítulo 1 - A UnB E O SEU CONTEXTO SOCIAL

- CARACTERÍSTICAS ESPECÍFICAS DO DF.

- PROJETO DE EXPANSÃO DA UnB E SUAS ÁREAS DE INFLUÊNCIA

Capítulo 2 - A ELABORAÇÃO DO ORÇAMENTO PÚBLICO .15

- LEGISLAÇÃO

- PLANO PLURIANUAL - PPA

- LEI DE DIRETRIZES ORÇAMENTÁRIA - LDO

-LEI ORÇAMENTÁRIA ANUAL - LOA

Capítulo 3 - DEFINIÇÃO DE PRIORIDADES E ENCAMINHAMENTO DE EMENDAS AO CONGRESSO. .19

- COMPOSIÇÃO E INJUNÇÕES POLÍTICAS NA COMISSÃO DE EDUCAÇÃO

Capítulo 4 - TABELA E ANÁLISE DE RESULTADOS DE 2000-2009. 23

- A RELAÇÃO ENTRE AS EMENDAS RECEBIDAS COM INVESTIMENTO NA UnB.

Capítulo 5 - ANDIFES E UnB - RESULTADOS .25

Capítulo 6 - UnB X IFES COM BANCADAS SIMILARES.

Capítulo 7 - UnB X IFES COM BANCADAS MAIORES .29

CONCLUSÃO. 31

BIBLIOGRAFIA. 34 


\section{INTRODUÇÃO}

Esta monografia tem como objeto estudar a relação da Universidade de Brasília com o Congresso nacional, especialmente em atividades que visam a influenciar a decisão no uso de recursos. Trata-se de uma pesquisa exploratória sobre como relacionar e influenciar o Legislativo em questões da Universidade pública brasileira, suas angústias, suas necessidades, enfim, como levar a educação com qualidade para uma boa parcela da nossa população carente de educação superior pública.

A questão da participação política no Legislativo tornou-se essencial após a promulgação da Constituição de 88. O eixo político transferiu-se do Executivo para o poder Legislativo. No Título VIII, Capítulo III da C.F., que trata da Educação, em seu Art. 207 ficou estabelecido que: “As universidades gozam de autonomia didático-científica, administrativa e de gestão financeira e patrimonial, e obedecerão ao princípio de indissociabilidade entre ensino, pesquisa e extensão"'.

Em 1998, passados dez anos da promulgação, a autonomia de gestão dos recursos financeiros ainda não havia sido regulamentada. A administração Superior da UnB, no final de 97, convidou-me para iniciar um processo de aproximação com o Legislativo federal, no intuito de demonstrar aos parlamentares a importância do relacionamento entre as instituições (UnB e Parlamento) e do projeto de expansão da UnB no contexto social do DF e Entorno. Afinal, é amplamente sabido que a administração pública só pode efetuar gastos previstos no orçamento público. Além disso, o sistema do orçamento público registra a execução orçamentária e controla a situação financeira e patrimonial das IFES.

Ao ingressar nessa nova função, percebi que havia uma gama de participações diferentes. Notei que a principal preocupação dos gabinetes parlamentares era com a chamada base eleitoral no Estado. Como o DF, por si, constitui em uma unidade da Federação distinta, sem municípios e conseqüentemente sem prefeitos nem vereadores, o papel de destaque nessa intrincada equação de interesses políticos se dava com o Governo do DF, que recebe recursos da União, através do Fundo Constitucional e de emendas parlamentares; da sociedade organizada e dos órgãos federais sediados na capital. E a UnB é um desses destaques. O meu papel era buscar estreitar o relacionamento da Instituição 
UnB com o Parlamento em geral, se possível, e em especial com a Bancada do DF, independentemente de qualquer coloração partidária e, ou, ideológica.

Para que pudesse ser reconhecido como interlocutor válido (representante da UnB) pelos parlamentares e seus assessores, assim como pelos órgãos da Casa e secretários das comissões de mérito foi necessário identificar-me como tal perante a Mesa Diretora da Câmara Federal. Esse credenciamento permite a possível colaboração entre as comissões e os públicos de interesse que giram (transitam) em torno delas (ONGs, movimentos sociais ligados à educação, empresas educacionais, comunidade acadêmica, ministérios afins etc.). Além das sessões normais das Comissões, constantemente promove-se audiências públicas de interesse dos parlamentares. É através desses eventos que os parlamentares podem ouvir o que os seguimentos organizados pensam sobre o assunto em pauta, no nosso caso o ensino superior público. Para o parlamentar, quanto mais gente houver e maior for à cobertura da mídia, seja ela interna ou externa, melhor se torna o evento.

Podemos notar que alguns parlamentares se identificam com certos grupos de interesse, são simpáticos a eles, têm prazer em apoiá-los e ajudá-los no que for necessário. E foi nesse sentido que comecei a afinar minha sintonia com esses parlamentares mais identificados com a questão do ensino superior, em especial com a pública. Este processo, além de ser demorado, muitas das vezes se torna infrutífero, porque, quando menos se espera, o parlamentar pode ser convocado a ocupar outra função pública (secretário ou ministro de estado) ou mesmo quando se renova através das eleições, de quatro em quatro anos, o mandato dos parlamentares. Com o deslocamento do poder para o Legislativo, a conseqüência desse processo foi que o acesso às autoridades e a informação se democratizaram. Com isso, a influência cresceu e continua crescendo a olhos vistos nos poderes constituídos ${ }^{1}$.

Aqui cabe uma discussão teórica sobre o tema grupos de pressão (ou lobby, como é tratado internacionalmente). A palavra lobby significa, em inglês, ante-sala, vestíbulo, e o seu uso na política surgiu nos Estados Unidos por indicar o local no Congresso norteamericano onde aconteciam muitas das atividades de persuasão de parlamentares sobre os mais diversos temas. Em sua origem, assim, o termo remete à atividade em local público e

\footnotetext{
${ }^{1}$ Poderíamos abrir um espaço neste trabalho, para discutirmos, a regulamentação do mesmo, que é objeto de tema tanto na sociedade quanto no Parlamento. Mas, este não é o objetivo desta monografia.
} 
conhecido sem que houvesse a necessidade de qualquer subterfúgio para a sua realização. Longe de ser algo secreto ou realizado fora do Congresso, o lobby, como o próprio nome revela, era atividade normal e regular.

Como diz Graziano, "Fazer lobby não é corrupção. Apesar de algumas 'áreas cinzentas', há uma clara percepção entre os representantes de interesses privados e as autoridades públicas dessa diferença. Não surpreende, portanto, que a área na qual o lobby e a corrupção se interpenetram de maneira mais perigosa seja a do financiamento de campanhas eleitorais". Assim, essa área cinzenta que menciona o autor não pode ser entendida como a prática regular feita no Congresso Nacional.

No entanto, naturalmente existem atividades ilícitas e que corrompem as instituições, mas essas, ao contrário do lobby, tal como o entendemos e como é utilizado na literatura corrente, são tão-somente corrupção. Não é por outro motivo que a palavra lobby e as suas derivadas (lobista etc.) possuem geralmente um caráter negativo na política brasileira. Entre nós, o termo é associado à utilização de formas ilícitas de influência em mecanismos de decisão com vistas a desviá-los dos seus objetivos precípuos. Dito de outra forma, o exercício do lobby seria algo necessariamente ligado à corrupção das instituições políticas. No entanto, essa visão negativa não é a que predomina na literatura sobre o tema e tampouco a que reflete a realidade da ação de grupos de pressão junto ao Congresso Nacional.

Por lobby (ou lobbying para ser mais preciso com o idioma inglês) se entende "o processo por meio do qual os representantes de grupos de interesses, agindo como intermediários, levam ao conhecimento dos legisladores ou dos decision-makers os desejos dos seus grupos" (BOBBIO, MATTEUCCI, PASQUINO, 2004). Como se verá mais adiante, a atividade por mim exercida no Congresso Nacional tem uma particularidade: o fato de eu não ser um intermediário, mas parte da instituição que represento. No entanto, o conceito se faz adequado porque, mesmo sendo parte da UnB, não sou que decide pela instituição. Neste sentido, atuo como intermediário entre aquelas pessoas e órgão da UnB que decidem as políticas da instituição e o Congresso Nacional.

Com efeito, a atividade exercida junto ao Congresso Nacional é bastante particular. Em tese de doutorado recentemente defendida na Unicamp, (Lobby e representação de 
interesses: lobistas e seu impacto sobre a representação de interesses no Brasil), a pesquisadora Andrea Cristina de Jesus Oliveira indica a existência de quatro modalidades de lobby — público, institucional, classista e privado. O que é realizado pela UnB pode, assim, ser considerado lobby público, no sentido de ser a defesa de interesse de uma universidade federal pública e em defesa de interesses públicos, e institucionais, porque o trabalho em grande medida consiste em indicar as necessidades e fazer os congressistas conhecerem a realidade da instituição.

Ainda sobre a atividade de lobby exercida pela UnB, é necessário citar que importantes trabalhos indicam que a defesa de interesses junto ao Congresso Nacional é atividade lícita e mesmo necessária para a democracia. Murillo de Aragão, em livro publicado a partir de pesquisa de mestrado realizada na $\mathrm{UnB}$, indica que mais de 383 grupos de interesse atuaram durante a elaboração da Constituição de 1988 para valer os seus interesses (Aragão, 1994). Se sempre tivemos a atuação de grupos de interesse no Congresso Nacional, foi na Constituinte que a sua importância no Brasil ficou clara. De lá para cá, em diferentes níveis e formatos, o Congresso Nacional viu em seus corredores diversos agentes trabalhando em defesa de instituições e interesses, e é justamente sobre a experiência de uma universidade pública federal nesta prática política e institucional que este trabalho versa.

Ao ingressar no curso de Gestão Universitária, do PROCAP/SRH da UnB, coordenado pela FACE - UnB pude vislumbrar que essas questões e conceitos tais como influência, participação política, sociedade organizada, ação coletiva, grupos de pressão, entre outros, fazem parte das ciências políticas, que buscam atualizar a visão de seus pesquisadores. Soma-se a isso o estudo desses termos ou de semelhantes em outras áreas do conhecimento - como a sociologia, as ciências da informação e da comunicação - e pode-se ter uma idéia da diversidade conceitual e teórica que se formou sobre o tema estudado exaustivamente por diferentes autores e áreas do conhecimento.

Esse processo permite focar na práxis, na observação, na descrição do processo, na análise do discurso verbal, ou seja, como se dá o espaço de interação entre a única Universidade pública no DF, a UnB, (já que o DF não possui sua Universidade Estadual, como em algumas outras unidades da Federação) e os seus representantes no CN (Bancada do DF). É necessário entender o processo legislativo. Como se dá a elaboração do 
orçamento público. Quais são suas etapas e como e quando intervir. Qual o (s) interlocutor (s) a ser (em) abordado (s). Como obter um bom resultado do seu trabalho profissional.

O objetivo geral da monografia é mostrar porque as universidades públicas, especialmente a UnB, devem investir na construção de canais de interação com o Poder Legislativo. As universidades, como todos os organismos vivos da sociedade precisam acompanhar os assuntos de seu interesse no Congresso Nacional no intuito de estreitar relações, especialmente com o governo federal, que é o mantenedor das Universidades Federais. O acompanhamento de assuntos que são pertinentes à Universidade Pública, utilizando um canal real, que é a presença de um representante da Universidade, atuando diretamente com os parlamentares, sem passar por um filtro (mídia, corporações -Andes, Fasubra, ANDIFES- parlamentares), pode contribuir para o fortalecimento do regime democrático? Será que a necessidade desta abordagem, que se convencionou denominar "lobby", é parte constitutiva do regime democrático? Para isso, as Universidades públicas investem na construção de um diálogo, através da ANDIFES, procurando recursos (emendas) junto as $\mathrm{CE}$ da $\mathrm{CD}$ e do SF, para o conjunto das universidades. A UnB investe também na construção dessa ponte junto a Bancada do DF, porque ela é a única universidade pública existente no DF e região. Se analisarmos o orçamento da universidade pública brasileira no período indicado, (2000-2009), vamos verificar que essa política estava levando a uma morte lenta e gradual do sistema público federal. A herança desse processo é só observar como se deu a expansão do ensino superior privado nos dois governos, tanto de FHC, como de Lula. A autonomia universitária jamais foi implementada por nenhum Governo Federal. O Governo prefere manter as IFES sob o olhar desconfiado de quem não pode administrar os recursos financeiros a sua disposição. O MEC continua administrando as IFES através de portarias, decretos e outros instrumentos de controle. Esses órgãos são muitas das vezes externos as universidades. Não permite o livre exercício orçamentário.

Nestes últimos anos, houve um crescimento do aporte financeiro, que resultou na expansão física da rede, onde o setor privado não interessou investir. Intensificou o ritmo do trabalho nas IFES, degradando as condições salariais dos trabalhadores em educação superior. Houve uma série de medidas no âmbito da legislação do ensino superior, que não resultou em uma política que implantasse a autonomia universitária que trata o art. 207 da Constituição. 
Todo o projeto de "reformas" apontavam para a legitimação do crescimento do ensino privado em nosso país, como é demonstrado na curva ascendente de matrícula no ensino privado em detrimento do público. Hoje, 75\% das matrículas do ensino superior estão concentradas nas escolas superiores privadas, enquanto que as públicas detêm somente $25 \%$ das matrículas. Dentro desse quadro adverso, como a UnB, poderia ousar em falar de expansão da graduação e da pós na sua região de influência, o DF? Como expandir para fora do campus Darcy Ribeiro em direção as outras regiões geográficas do DF? Como ousar em construir novos campi com o orçamento em declínio ou mesmo estagnado? Como fazer a expansão e manter a qualidade no ensino, em tempo de crise da universidade pública? Essa situação de crise orçamentária e financeira, pela redução dos recursos destinados as IFES, prejudicando a manutenção e expansão do ensino superior público pelo MEC agravou a situação existente.

Nestes últimos quatro anos de governo, (governo Lula) tentou-se reverter esta tendência trazendo um pouco de alento para as universidades públicas. Ampliou-se o financiamento (orçamento) permitindo que as IFES públicas aumentassem o número de matrículas e investissem na ampliação física e contratação de mais docentes e técnicos que pudessem dar sustentação ao crescimento atual.

A questão básica é a seguinte: Como a UnB poderia ousar em expandir sua área de influência, construindo e criando novos cursos para a sociedade, em tempos de crise orçamentária e financeira? Se não o fizesse, ficaria isolada na sua ilha (Campus Darcy Ribeiro no Plano Piloto) e deixaria os grandes aglomerados urbanos, com grande parcela de jovens pressionando pelo ensino superior, nas mãos das empresas privadas da educação. Para atender essa grande pressão social, a UnB necessitava de recursos, que o governo não colocava, ou coloca de maneira insuficiente no orçamento da FUB. Para resolver essa situação, recorremos principalmente ao apoio dos parlamentares do DF, no sentido de fazer emendas de Bancada e individuais para que pudéssemos atender a sociedade, que clamava pela expansão do ensino superior público no DF e região. Se o Estado brasileiro suprisse as IFES com a quantidade de recursos necessários para atender a sociedade, não seria necessário a ANDIFES buscar emendas de Comissão tanto na CD quanto no SF para poder cumprir a sua missão, que é oferecer ensino gratuito e de qualidade a sociedade brasileira. O mesmo acontece com a UnB. Se a instituição tivesse recursos em quantidade suficiente 
para a sua expansão, ou mesmo para sua manutenção cotidiana (custeio), haveria necessidade de um trabalho como esse, de se relacionar com o $\mathrm{CN}$ a procura de recursos e complementar o seu orçamento para realizar a expansão na sua região de influência? Há uma grande contradição nesse processo: Uma universidade pública (UnB) teoricamente não necessitaria influenciar os parlamentares no $\mathrm{CN}$ no sentido de complementar seu orçamento. Bastaria o governo cumprir com a sua obrigação, que é oferecer recursos em quantidade e em tempo hábil para as IFES, que este processo seria desnecessário. Neste sentido, há uma necessidade de um amplo debate sobre a questão da autonomia universitária, como propugna o art. 207 da CF. Esse modelo de orçamento, onde a burocracia estatal contingência os recursos da universidade, inclusive os gerados com recursos próprios, não serve para um projeto de universidade autônoma.

Essa situação nos leva a fazermos esse tipo de trabalho que na realidade seria desnecessário, se o governo tratasse a educação como prioridade. Deve-se entender aqui, essa influência, como uma categoria de valor neutro de participação política de entidades representativas no âmbito das comissões de mérito (Educação, Orçamento) do Legislativo.

A entidade representativa que faz a defesa das IFES no âmbito do $\mathrm{CN}$ é a ANDIFES. Ela representa o conjunto das universidades federais do país, portanto a UnB também. Porém, a ANDIFES ao fazer a defesa da coletividade, consegue incluir anualmente apenas uma emenda de Comissão, da CE, que pode ser da CD ou do SF. Esta emenda a LOA, é dotada no MEC, para ser distribuída ao conjunto das IFES, de acordo com o peso de cada universidade, em uma matriz desenvolvida para esse fim. Para a UnB, por se tratar de um montante muito aquém das suas necessidades, esse valor não é o suficiente para os investimentos necessários a aplicação em ensino, pesquisa e extensão, quanto mais para sua expansão.

É neste contexto que a UnB trabalha para influenciar os parlamentares sensíveis à sua missão. Esse processo deverá ser compreendido detalhadamente, sobre os atores que participam ou deveriam participar em torno das comissões de mérito da CD e SF. É legítima a participação da UnB, nesse processo? Há um dado interessante nesta situação. Pela proximidade física da $\mathrm{UnB}$ com o $\mathrm{CN}$, muitos dos componentes da comunidade (professores, funcionários, estudantes) através de suas entidades sindicais, ou mesmo, grupos com interesses diversos, procuram os parlamentares, como se fossem representantes 
institucionais, às vezes confundindo os parlamentares (a Bancada) como se o seu pleito, legitimo, diga de passagem, fosse o pleito da Instituição UnB. Quem decide quais pleitos são válidos para a UnB, é a Administração Superior da mesma e não parte integrante da comunidade, por mais legítima que seja. Por isso, a denominação "entidade representativa" (credenciamento do seu representante-assessoria parlamentar) é considerada mais apropriada a este trabalho que grupos de interesse ou grupos de pressão.

Também, o poder de influenciar é estudado e, definido neste trabalho como conjunto de habilidades que visa a influenciar os tomadores de decisão do Poder Legislativo a fazer ou deixar de fazer algo de interesse das entidades representativas. 


\section{Capítulo 1 - A UnB E O SEU CONTEXTO SOCIAL}

Fundada em 1962, seu campi principal que leva o nome de um dos seus fundadores “Darcy Ribeiro”, está localizado muito próximo do centro do poder do país. Esta proximidade ao Palácio do Planalto e do Congresso Nacional, levou algumas autoridades na época resistirem à sua construção. Não queriam que os estudantes da UnB pudessem interferir na vida política da cidade e do país. Após negociações, o Presidente João Goulart sancionou a Lei 3.998, em 15 de dezembro de 1961, homologada pelo Decreto n. 500 de 15 de janeiro de 1962.

Reza em seu estatuto, art. 3o. que "são finalidades essenciais da Universidade de Brasília o ensino, a pesquisa e a extensão, integrados na formação de cidadãos qualificados para o exercício profissional e empenhados na busca de soluções democráticas para os problemas nacionais."

O modelo inspirador da UnB, segundo seus fundadores, deveria ser diferente dos modelos das décadas passadas que inspiraram à construção de outras universidades no país. A UnB nasceria sob a égide da transformação que embalava o sonho criador da nova capital. Com a visão criadora de Anísio Teixeira, fundou-se a primeira universidade com institutos centrais e faculdades no país. Neste sentido, criaram-se cursos troncos, para formação básica, e após a conclusão, em média dois anos, os alunos seguiam para suas faculdades/institutos. Dessa forma romperiam com a antiga visão de cátedra, modelo até então predominante no ensino superior no Brasil.

A UnB é uma das mais conceituadas instituições de ensino superior do Brasil. Possui um orçamento anual segundo a LOA de 2010, de 978 milhões de reais, sendo que destes, 551 milhões para pessoal e encargos sociais, 355 milhões para outras despesas correntes, 111 milhões para investimentos, 0,2 milhões inversões financeiras. O PLO 2010 propunha inicialmente 88 milhões para investimentos. Após a nossa intervenção durante o processo orçamentário, a LOA 2010, em execução neste ano, saltou para 111 milhões de investimento, obtendo um quantitativo de 23 milhões, entre emendas de bancada (coletiva) e individuais, totalizando mais que um quarto do proposto pelo Executivo em sua proposta inicial. 
Sua área física é composta pelos campi Darcy Ribeiro, UnB/Planaltina, UnB/Ceilândia e UnB/Gama. Possui em torno de 1,9 mil docentes, 2,3 mil técnicoadministrativos, mais de 27 mil alunos, em 103 cursos de graduação diurnos e noturnos, 73 de especializações, 67 cursos de mestrado, 51 de doutorado, com uma estrutura organizacional das mais complexas.

\section{- CARACTERÍSTICAS ESPECÍFICAS DO DF.}

As características econômicas, demográficas e sociais do DF, bem como a localização geográfica da UnB, e sua proximidade com o $\mathrm{CN}$, fazem dela uma instituição de ensino superior privilegiada junto aos parlamentares em geral e aos congressistas do DF em particular. A UnB não poderia deixar de atuar junto ao $\mathrm{CN}$ de maneira concreta $\mathrm{e}$ sistemática para tirar proveito dessa situação.

Nas duas últimas décadas, houve uma expansão do ensino superior privado em detrimento do ensino público no país. No DF, a situação não foi diferente. Pensando no seu futuro, a UnB começou a planejar o seu crescimento, para sair do seu limite físico e geográfico da ocupação no Plano Piloto. A sociedade iniciou uma discussão sobre o tamanho da população universitária no país, através do PNE, e constatou que a nossa juventude universitária está quantitativamente abaixo dos nossos vizinhos na América Latina. No DF está comprovado que é a unidade da federação com a menor taxa de matrícula no ensino superior público do país. Esta situação é real porque só existe uma universidade pública atuando no DF que é a UnB. Os diversos governos do DF não criaram sua Universidade pública, como ocorreu em outras unidades da federação. A taxa de crescimento populacional da região do entorno do DF foi uma das maiores do país.

\section{- PROJETO DE EXPANSÃO DA UnB E SUAS ÁREAS DE INFLUÊNCIA}

O Plano de expansão da UnB em direção às cidades pólos são frutos de esforços da própria universidade junto com membros dessas comunidades que desejavam a instalação da UnB em suas proximidades, além dos apoios imprescindíveis da Câmara legislativa do DF e da Bancada federal do DF na Câmara e no Senado Federal, e do GDF. A instalação de três unidades nas cidades satélites do DF: Planaltina, Ceilândia e Gama. O primeiro campus, o de Planaltina, beneficiou uma população de mais de meio milhão de habitantes, 
abrangendo as regiões administrativas de Sobradinho, Planaltina, Brazlândia, Sobradinho II além dos municípios limítrofes do DF de Formosa, Cabeceiras, Planaltina de Goiás, Vila Boa e Água Fria e o município mineiro de Buritis. O campus universitário UnB Ceilândia / Taguatinga abrange as regiões administrativas de Ceilândia, Taguatinga, Riacho Fundo, Recanto das Emas, Samambaia e Águas Claras, e os municípios de Mimoso de Goiás, Padre Bernardo, Cocalzinho, Águas Lindas, Corumbá, Alexânia e Abadiânia. E por último, o campus UnB - Gama, abrangendo as regiões administrativas de Gama, Santa Maria, São Sebastião, Paranoá, e os municípios de Cristalina, Luziânia, Valparaíso, Novo Gama, Cidade Ocidental, Santo Antonio do Descoberto, e os municípios mineiros de Cabeceira Grande e Unaí. 


\section{LEGISLAÇÃO}

Por se tratar de universidade federal, a UnB é diretamente afetada pelo orçamento público. Assim, na presente parte, descreveremos como se dá o processo orçamentário público no Brasil. A Constituição de 88 impôs uma dinâmica para construção do ciclo orçamentário. Para torná-lo mais transparente e democrático o Título VI - Capítulo II Seção II - no seu principal artigo, o Art. 165, descreve basicamente que os projetos de lei relativos aos três itens especificados - o plano plurianual (PPA), as diretrizes orçamentárias (LDO) e os orçamentos anuais (LOA) - devem ser apreciados conjuntamente pelas duas casas do Congresso Nacional, por meio da constituição de uma Comissão Mista de Orçamento, cumprindo determinação prevista no Art. 166, parágrafo $1^{\circ}$ da CF. Esta comissão é composta por 40 parlamentares, sendo 30 deputados e 10 senadores, com igual número de suplentes. Os parlamentares são escolhidos segundo a representatividade de cada bancada ou bloco partidário nas duas casas do $\mathrm{CN}$. Esses membros não podem ser fixos, obedecendo à rotatividade conforme preceitua o RI e resoluções da Comissão Mista Permanente de Planos, Orçamentos Públicos e Fiscalização do CN. É necessário conhecer o processo orçamentário, ou seja, seus atores (parlamentares - deputados e senadores), assessoria técnica, assessoria parlamentar, seus prazos, sua forma de tramitação, sua execução para que possamos acompanhar e manter um controle social dos recursos envolvidos no orçamento público em nosso país. Segundo alguns atores envolvidos no processo legislativo, estas peças (PL orçamentários) são as mais importantes que tramitam no $\mathrm{CN}$.

\section{- PLANO PLURIANUAL - PPA}

Quando um governo assume o controle do Estado, ele executa no seu primeiro ano de governo, o orçamento decidido e votado pelos parlamentares que estão no seu último ano de mandato. Portanto, a execução orçamentária se dá de acordo com o Plano Plurianual (PPA) vigente. O PPA é o instrumento de planejamento, no qual o governo apresenta suas propostas de ação, para implementar políticas públicas. O prazo é de quatro anos, contém objetivos e metas para os programas de governo. O PPA inicia no segundo ano de um governo e encerra ao fim do primeiro ano do próximo governo. 
Para que a proposta tenha agilidade, subdivide-se a mesma em várias relatorias setoriais. A que nos interessa é a relatoria de Educação, Cultura, Ciência e Tecnologia. É nesta relatoria que são definidos os programas relacionados à Educação de uma forma geral, e o ensino superior em particular. Todo o planejamento governamental para a nossa área de atuação é definido neste instrumento. Caso a Educação Superior não seja priorizada neste plano de governo, devemos procurar o relator setorial e influenciá-lo no sentido de contemplar com mais desenvoltura o ensino superior em seu relatório. Essas emendas ao PPA deverão ser feitas nesse período, porque se passar essa oportunidade, o processo de emendas ao projeto se tornará mais difícil de ser implementado no plenário da $\mathrm{CMO}$ ou mesmo no plenário do $\mathrm{CN}$. É nessa ocasião que observamos se o governo eleito vai ou não priorizar a Educação como um todo, ou a Educação Superior em particular, e se existe previsão de gastos suficientes no respectivo Ministério.

\section{- LEI DE DIRETRIZES ORÇAMENTÁRIA - LDO}

O Projeto de Lei de Diretrizes Orçamentárias é encaminhado anualmente ao $\mathrm{CN}$, pelo Executivo, até o dia 15 de abril para discussão e aprovação no primeiro semestre de cada ano, sob pena de o $\mathrm{CN}$ não entrar em recesso, com o objetivo de dar a direção à elaboração da LOA. É neste PL, que quanto às metas e prioridades se dá precedência aos programas na alocação de recursos. É na LDO que fixa as metas e prioridades da administração federal para o ano seguinte. Se a Educação Superior não estiver contemplada nas regras e nos anexos da LDO, ela pode ficar impedida de receber recursos do orçamento. É na CMO que se apreciam as emendas ao projeto. Entender o funcionamento da LDO é importante para que a população possa garantir e cobrar previsões de recursos para a Educação como um todo e o ensino superior em particular. Por isso, precisamos estar atentos a essa tramitação para que possamos influenciar neste momento no processo que servirá de base para a construção da LOA. 


\section{- LEI ORÇAMENTÁRIA ANUAL - LOA}

A Lei Orçamentária Anual (LOA) tem por objetivo estimar a receita e fixar o valor das despesas da União. Todos os gastos dos poderes da União estão inclusos nesta proposta. Este projeto é encaminhado ao $\mathrm{CN}$ pelo Executivo até o dia 31 de agosto do ano anterior. A proposta apresentada deve ter compatibilidade com os programas existentes no PPA. Nos anexos ao PL devem conter as previsões de receitas, bem como as de despesas descriminadas por: grupo de natureza de despesa (pessoal e encargos, investimento, etc); por órgão e suas unidades (fundações, autarquias, etc); por funções, subfunções, programas e projetos/atividades/operações especiais. Cada item recebe uma identificação numérica. Por exemplo:

1) órgão: Ministério da Educação (26);

2) unidade orçamentária: Fundação Universidade de Brasília (26.271);

3) função: educação (12);

4) sub-função: ensino superior( 364);

5) programa: expansão do ensino superior no DF (1073);

6) projeto/atividade/operações especiais: expansão do ensino superior - Campus de Planaltina - Campus do Gama - Campus de Ceilândia - no Distrito Federal $(6956 / 57 / 58)$

São milhares de projetos (duração determinada), de atividades (duração continuada). Tanto o PPA quanto a LOA possuem um processo de tramitação semelhante. Escolhido o relator-geral pelo partido ou bloco partidário constituído em ambas as Casas (obedece a rodízio - deputado em um ano, senador em outro, e vice-versa), este delega competência para os relatores setoriais, que se responsabilizam por áreas temáticas, iguais as apresentadas para o PPA. Constituem-se um calendário que estabelece prazos para emendas, que podem ser coletivas (bancadas estaduais - por ex. Bancada do DF - ou de Comissão - por ex. Comissão de Educação da CD ou SF) ou individuais, podendo as mesmas incluir, alterar ou suprimir texto e/ou valores no PL.

À medida que o PL da LOA inicia sua tramitação e é distribuído por áreas temáticas, é nessa ocasião que os parlamentares são influenciados a apresentarem propostas de alterações mediantes emendas. É nesse momento em que a proposta orçamentária está mais 
suscetível a ação de grupos pressão, ou de interesse, na forma de incluir, ampliar ou mesmo suprimir algo em função de seus projetos de interesse.

Nesse processo, podem surgir algumas práticas políticas, que colocam em desconfiança a transparência do orçamento. $\mathrm{Na}$ década de 90 , aconteceu vários orçamentos serem votados fora do prazo constitucional. Devido à possibilidade de o orçamento não ser votado até o final do ano, incluem-se na LDO mecanismos de execução, de parte do mesmo, de forma que o governo não fique engessado na sua administração. É possível o $\mathrm{CN}$ permitir tais mazelas. Outro ponto controverso na questão orçamentária é se o orçamento é autorizador ou impositivo. Muitos defendem a tese de que o $\mathrm{CN}$ ao aprová-lo, o mesmo passa a ser lei, portanto é impositivo. Mas para o Executivo, a LOA aprovada trata-se apenas de uma autorização, cabendo ao governo executá-lo da melhor forma que lhe convier. Neste contexto, via de regra, após a aprovação, pode haver contingência dos recursos, não obedecendo, o teor da lei e as modificações realizadas pelo Legislativo. $\mathrm{O}$ contingenciamento é nada mais que a impossibilidade de se realizar determinados gastos que não interessam ao governo. É mais uma forma do Executivo manter o orçamento sob controle. Outro mecanismo utilizado de forma abusiva pelo Executivo é alterar o orçamento aprovado pelo $\mathrm{CN}$ por Medida provisória.

É importante a participação política das entidades ligadas diretamente ao ensino superior tais como a ANDIFES, ANDES, FASUBRA, no âmbito das CE e CMO da CD e SF. Essa participação deveria ocorrer tanto na elaboração, quanto na tramitação pelo $\mathrm{CN}$ e também na execução. Como isso não ocorre de uma forma sistemática por estas entidades, a UnB, participa de forma ativa nesse processo procurando influenciar principalmente os parlamentares da Bancada do DF, de modo que a mesma obtenha uma relação próxima ao interesse dos parlamentares junto a sua base social. 

AO CONGRESSO

As demandas dentro da Universidade são definidas pelos órgãos colegiados superiores e incluídas como pontos constitutivos do P.D.I. da UnB para um determinado período. Essas demandas implicam em obtenção de recursos orçamentários e financeiros para que possam ser implementadas.

Sendo a UnB uma instituição federal pública, a principal fonte de recursos é o Orçamento da União, o qual está subordinado ao Congresso Nacional que o discute, o organiza e vota a LOA no âmbito da Comissão Mista de Planos, Orçamentos Públicos e Fiscalização do Congresso Nacional. A Administração Superior da UnB determina quais as prioridades da instituição, apresentando as mesmas à Bancada do DF, através de um pedido de inclusão do projeto nas emendas que podem ser individuais, de comissões e de bancadas.

As emendas individuais são emendas de pequeno porte financeiro, que geralmente são distribuídas pelo parlamentar de acordo com seus interesses eleitorais junto à comunidade. No período analisado a universidade tem sido aquinhoada por diversas emendas individuais dos parlamentares do DF, e até mesmo de outros Estados da federação.

As emendas de comissões são aquelas em que as Comissões do $\mathrm{CN}$ alocam recursos de porte maior, junto aos seus ministérios correspondentes, para que estes desenvolvam projetos estruturantes para o país em suas respectivas áreas de atuação. São exemplos de emenda de comissão as emendas que a ANDIFES obtém para serem alocadas no MEC e posteriormente utilizadas no ensino superior do país.

As emendas de bancadas são aquelas em que os parlamentares de cada UF alocam recursos de grande monta para serem aplicadas no estado da respectiva bancada. A UnB com o seu processo de aproximação junto ao $\mathrm{CN}$ tem sido beneficiada anualmente por essa modalidade de emenda. 
Para que a UnB possa obter sucesso nesse processo, é necessário organizar reuniões com a bancada, de forma que ela, além de conhecer o pleito da Universidade para aquele ano, possa defendê-la junto aos pares. A bancada tem direito a apresentar ao orçamento uma quantidade de emendas, para beneficiar a sociedade, que podem variar no valor anualmente conforme a situação da economia que o país esteja vivenciando. No caso do DF, a bancada pode beneficiar outros setores da sociedade, que necessariamente não precisa ser o ensino superior. A bancada pode escolher qualquer setor social. Diante dessa realidade, é necessário que a UnB intervenha nesse processo, defendendo seu projeto institucional para que parcela desses recursos venham ser utilizada para o desenvolvimento da atividade fim da UnB.

Após aprovado pedido de emenda pela bancada, a emenda da UnB é incluída no conjunto de emendas de bancada do DF e é encaminhado à Comissão Mista de Orçamento (CMO) para que a mesma seja apreciada por esta comissão, que é ela quem diz se há ou não recursos orçamentários para atende-la, seja parcial ou totalmente.

Esse processo exige acompanhamento, pelos seguintes motivos:

1) existem possibilidades de cortes pelo relator setorial (Educação, Cultura, Ciência e Tecnologia e Esporte) que é o parlamentar, que procura adequar, os pedidos ao volume de recursos que ele tem para atender a sua área, que normalmente é inferior ao demandado.

2) havendo corte profundo na emenda de bancada da UnB, é preciso recorrer ao relator setorial, utilizando um recurso que no parlamento, chama-se destaque. É nesse momento que vamos tentar recompor a nossa emenda, conforme construída pela UnB e apresentada pela Bancada do DF.

3) após aprovação ou rejeição do destaque, passa-se o processo para o relator geral do orçamento.

Para se obter sucesso nesse processo, faz-se necessário conhecer o rito, prazos e pessoas envolvidas na construção da peça orçamentária. A competição entre os órgãos públicos federais dos poderes constituídos situados no DF, por emendas no orçamento, obriga a UnB construir uma relação estreita com a Bancada no $\mathrm{CN}$. 
Esse é um trabalho suprapartidário, consistente que ao longo dos anos tem obtido bons resultados para a Instituição. Dentre os benefícios podemos citar: aquisição de equipamentos, construção/reformas para o Hospital Universitário de Brasília (HUB), obras para expansão dos três campi, (Planaltina, Ceilândia e Gama) custeios dos cursos de graduação e laboratórios, laboratórios para atividades de pesquisa, reforma e modernização de infra-estrutura física da $\mathrm{UnB}$, contribuindo desta maneira para atividade fim da universidade, ou seja, ensino, pesquisa e extensão.

\section{COMPOSIÇÃO E INJUNÇÕES POLÍTICAS NA COMISSÃO DE EDUCAÇÃO}

As C. E. da Câmara e do Senado Federal têm como rito oferecer cinco emendas anuais destinadas à Educação e também a Cultura no país. Nos últimos sete anos (2003 2009), a CEC foi a responsável pela inclusão das emendas destinadas ao ensino superior.

Essas cinco emendas destinam-se à Educação Fundamental e Básica, Educação Tecnológica, Educação Superior e duas emendas à Cultura.

Esse rito é fruto de um acordo dentro da Comissão, porém pode variar anualmente de acordo com interesses dos membros que a compõe. A composição da C. E. , assim como todas as outras comissões existentes no Congresso Nacional é designada pelos partidos ali representados, a cada quatro anos, obedecendo ao peso de cada bancada partidária (número de deputados eleitos na eleição anterior).

Durante a mesma legislatura, a composição da C. E. pode sofrer mudanças no seu quadro partidário, através de remanejamentos ou até mesmo substituições; realizadas pelos líderes partidários, porém, sem sofrer alterações na quantidade de parlamentares.

Consequentemente, uma mudança de composição pode alterar a correlação de forças dentro da C. E., tendendo ora na defesa do ensino público e gratuito, ora na defesa do ensino privado. 
Dentro desses dois universos (o público versus o privado) surgem parlamentares que defendem o ensino público com ênfase na educação fundamental em detrimento do ensino superior e vice-versa.

Durante o período observado (2000-2009) neste trabalho, ocorreram duas eleições gerais o país. Na eleição de 2002, assim como na de 2006, o Congresso foi renovado em torno de $50 \%$ de sua composição, como ocorre tradicionalmente. Isso acarreta em três composições diferentes no período estudado, ou seja, 2000 até 2002, de 2003 a 2006 e do ano de 2007 a 2009.

Portanto, a composição da Comissão é alterada a cada ano, implica muitas vezes em relacionamentos favoráveis à Instituição, pois a Educação é sempre um tema nobre; em outros momentos, simpáticos, porém com interesses que atropelam o tema. 
Dados da Diretoria de Contabilidade e Finanças (DCF) do Decanato de Administração da UnB demonstram que no período de 2000 à 2009, a Universidade de Brasília foi beneficiária de diversas emendas tanto individuais quanto de Bancada do DF. Ao analisarmos o quadro acima, constatamos que a previsão de crédito orçamentário era de um total de R\$ 103.563967,00 milhões, (já incluído os valores de 2010) sendo que o total de crédito autorizado para empenho foi da ordem de R\$ 45.295.771,63 milhões, (já incluído os valores de 2010) destes $\mathrm{R} \$ 34.850 .901,64$ para obras e $\mathrm{R} \$ 10.444 .869,99$ para custeio/investimento em diversos projetos da UnB. (vide TAB. 1) Podemos destacar que os projetos de expansão da UnB tanto em Planaltina como o campus do Gama e de Ceilândia/Taguatinga foram os que mais receberam recursos dos parlamentares da Bancada do DF. Este fenômeno pode ser explicado pela tendência do político querer responder com mais efetividade ao crescimento da UnB junto a comunidade brasiliense. O parlamentar se sensibiliza mais com a pressão da sociedade em busca de ensino superior para o seu potencial eleitorado.

TAB. 1. - Emendas Parlamentares destinadas à FUB

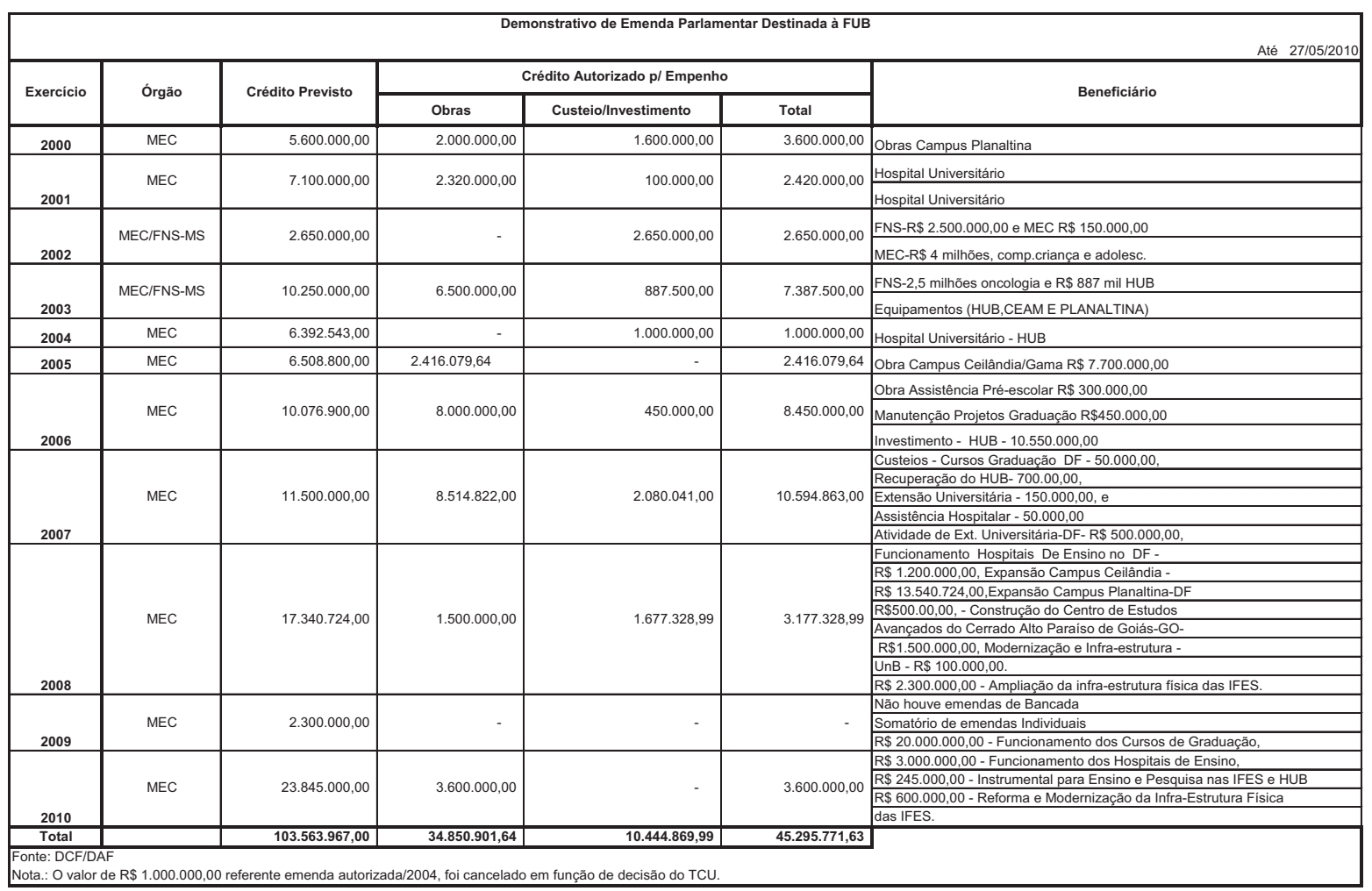


A criação desses três novos Campi da UnB no DF foi fruto de um processo que envolveu apoio da Câmara Legislativa do DF, da bancada federal do DF na Câmara e no Senado Federal, além governo do DF e também a participação de membros das comunidades dessas localidades. Essas novas unidades acadêmicas da UnB serão importantes para o desenvolvimento socioeconômico dessas localidades bem como dos municípios vizinhos dos Estados de Goiás e de Minas Gerais. Essas emendas que a Bancada do DF colocou em prol da UnB, foram aplicadas em obras de infra-estrutura e também para aquisição de mobiliário e instrumentos de instalação da sede nessas localidades. O trabalho até aqui realizado é fruto de um esforço coletivo, de modo suprapartidário, onde cada um dos atores envolvidos com seu elevado espírito público, está contribuindo para a expansão do ensino superior público, gratuito e de qualidade em todo o DF. Esta é uma causa social, que somente com o engajamento da sociedade é possível realizarmos esta tarefa.

\section{A RELAÇÃO ENTRE AS EMENDAS RECEBIDAS COM INVESTIMENTO NA UnB.}

Se analisarmos o orçamento anual da UnB, no desse período de 2000 à 2009, veremos que a maior parte desse orçamento está reservado para pagamento de pessoal e encargos sociais, outra grande parcela está na rubrica outras despesas correntes. Retirando a parcela de recursos próprios arrecadado, sobra-se muito pouco para a rubrica investimento. Se compararmos o que a UnB recebe de emendas parlamentares com o que sobra do seu orçamento para investir, vamos constatar que a proporção é muito forte. A título de exemplo: o Projeto de Lei Orçamentário deste ano -2010, contempla R\$ 88 milhões para investimento na UnB. A emenda de bancada para 2010 é de $\mathrm{R} \$ 23$ milhões, o que demonstra que a emenda é próxima de $25 \%$ do total de investimento este ano para o processo de modernização da UnB. $\mathrm{O}$ investimento proporcionado pelas emendas parlamentares é muito importante para o processo de ensino, pesquisa e extensão da UnB. Várias são as emendas para Hospital Universitário (HUB) que tem uma função assistencialista para a população carente do DF e região metropolitana. Também são contempladas emendas para manutenção de projetos de graduação, para extensão universitária, além de vários outros projetos implementados pela Administração Superior da Universidade. Portanto, a relação de aproximação com o CN, com discrição, sem alarde e sem cor partidária, tem rendido bons resultados à universidade, contribuindo assim para concretização de sonhos, tais como o projeto de expansão da UnB no DF. 
Capítulo 5 - ANDIFES E UnB - RESULTADOS

Há que considerarmos como referido anteriormente, que a ANDIFES também atua no $\mathrm{CN}$ no sentido de direcionar recursos para as universidades federais.

Analisando o período compreendido entre os anos de 2000 a 2009, observamos que o conjunto das IFES neste intervalo, representado pela ANDIFES no âmbito das Comissões de mérito da Câmara dos Deputados e Senado Federal, apresenta um montante aproximado de R\$ 361 milhões em emendas colocadas no MEC para distribuir ao conjunto de 55 Universidades Federais no país.

TAB. 2 - UnB X ANDIFES

Comparativo entre UnB e Andifes

\begin{tabular}{|c|c|c|c|c|c|c|c|c|c|c|c|}
\hline & \multicolumn{3}{|c|}{$1^{0}$ período legislativo } & \multicolumn{4}{|c|}{$2^{0}$ período legislativo } & \multicolumn{3}{|c|}{$3^{\mathrm{D}}$ período legislativo } & \multirow[b]{2}{*}{ Total } \\
\hline & 2000 & 01 & 02 & 03 & 04 & 05 & 06 & 07 & 08 & 09 & \\
\hline UnB & $5.600 .000,00$ & $7.100 .000,00$ & $2.650 .000,00$ & $10.250 .000,00$ & $6.392 .543,00$ & $6.508 .800,00$ & $10.076 .900,00$ & $11.500 .000,00$ & $17.340 .724,00$ & 0,00 & 72.118.967,00 \\
\hline Andifes & 0,00 & 0,00 & 0,00 & $7.000 .000,00$ & $1.000 .000,00$ & $275.000 .000,00$ & \begin{tabular}{|l|}
$48.880 .347,00$ \\
\end{tabular} & $65.000,00$ & $15.000,00$ & $30.000 .000,00$ & $361.960 .347,00$ \\
\hline
\end{tabular}

A ANDIFES obtém anualmente, através de gestões junto às $\mathrm{CE}$ da $\mathrm{CD}$ e do $\mathrm{SF}$, junto à LOA, emenda coletiva nacional para o funcionamento das IFES, cujos valores variam de ano a ano.

Durante período estudado, a coleta de dados realizada junto à Comissão Mista de Orçamento do $\mathrm{CN}$ demonstrou que:

1. A ANDIFES não obteve emendas nos três primeiros anos analisados (2000 a 2002), coincidindo com o primeiro período legislativo do intervalo de tempo em questão. (vide tabela 2).

Neste mesmo período (2000 -2002) a UnB obteve três emendas.

2. No segundo período legislativo, tanto a ANDIFES, quanto a UnB conseguiram suas quatro emendas de bancada no tempo em questão.

3. No terceiro período legislativo, a ANDIFES conseguiu três emendas e a UnB somente duas. 
Resumindo, a ANDIFES obtém junto à Comissão de Educação e Cultura - CEC, um total de R\$ 361.960.347,00, valor este destinado a um conjunto de 55 IFES, incluindo a UnB, ao longo de sete anos (2003-2009), o que não quer dizer que este valor tenha sido liberado pelo Executivo, pelo fato do orçamento a União ser uma peça autorizativa, ou seja, o CN autoriza o Executivo a executar o orçamento anual sem a obrigação de liberar as emendas no seu total. O orçamento público brasileiro não é impositivo, e sim autorizativo.

A UnB alcançou um montante de $\mathrm{R} \$ 72.118 .967,00$ ao longo de nove anos (20002008), porém destinando este valor exclusivamente à instituição, o que representa aproximadamente $20 \%$ do valor alcançado pela ANDIFES destinado a todas as IFES. Esta aproximação da UnB junto ao Congresso Nacional, pleiteando suas emendas à bancada do DF, não significa uma competição com a ANDIFES, antes tudo uma maneira complementar ao seu trabalho.

Como se pode concluir da analise dos dados acima descritos, a atuação da UnB junto ao CN não é apenas complementar ao trabalho da ANDIFES, como permite um ganho adicional substancial de recursos pela universidade federal do DF. 


\section{Capítulo 6 - UnB X IFES COM BANCADAS SIMILARES}

A análise de dados da influência da UnB sobre a Bancada do DF pode ser mais bem visualizada se compararmos com a atuação de outras universidades federais.

A estratégia de abordagem à bancada do Distrito Federal pela UnB, reivindicando emendas, tem resultado ao longo dos anos, em valores que contribuem para Instituição manter o ensino, a pesquisa, e a extensão.

Outras IFES têm ao longo desse período utilizado esse mecanismo para buscar suas emendas junto às suas bancadas estaduais; é o que demonstram os dados revelados pelo site do Congresso Nacional. Coletou-se também junto ao site o número de parlamentares por bancada de cada Unidade da Federação. Surgiu daí um universo que varia entre um mínimo de 8 (oito) e um máximo de 70 (setenta) deputados federais num total de 513 (quinhentos e treze) parlamentares.

A partir daí, foi feito um corte de forma que houvesse ao menos 1 (um) representante de cada região do país.(vide Tab. 3 ).

Logo, estando a UnB sediada no DF, detentor da menor Bancada representativa (8 deputados e 3 senadores), a instituição destaca-se entre as IFES 'afilhadas' de bancadas similares. (vide Tab. 3)

Tab.3 - Comparativo entre a UnB e IFES com bancadas similares por região

\begin{tabular}{|c|c|c|c|c|c|c|c|c|c|c|c|c|c|}
\hline \multicolumn{14}{|c|}{ DMB PARLAMENTARE } \\
\hline & & \multirow{2}{*}{ IFES } & \multicolumn{3}{|c|}{$1^{\circ}$ periodo legislativo } & \multicolumn{4}{|c|}{$2^{0}$ periodo legisativo } & \multicolumn{3}{|c|}{$3^{0}$ periodo legisativo } & \multirow[b]{2}{*}{ Total } \\
\hline & & & 2000 & 01 & 02 & $\mathscr{W}$ & 04 & $\omega$ & 06 & 07 & $Q B$ & 09 & \\
\hline 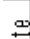 & Distrito Federal(8) & UnB & 5.600.000,00 & $7.100 .00,00$ & $2.650 .000,00$ & $10.250 .000,0$ & $6,392543,00$ & $6.508 .000,00$ & 10076900,00 & $11.500 .000,00$ & $17.340 .724,0$ & 0,00 & $77.418 .967, \infty$ \\
\hline 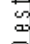 & Mato Grosso do Sul (8) & Fund.UFMS & $\begin{array}{r}0,00 \\
\end{array}$ & 0,0 & 0,00 & 0,0 & & 0,00 & 0,00 & 0,00 & 0,00 & 0,00 & 0,0 \\
\hline$\stackrel{\circ}{=}$ & Goiás (17) & UF $G 0$ & 0,00 & $0, \infty$ & 0,00 & 0,0 & 0,00 & 0,00 & 0,00 & $15.000 .000,00$ & $11.238 .896,0$ & 17.56360300 & $43.8 C 2,49,0$ \\
\hline $\begin{array}{l}5 \\
.\end{array}$ & Mato Grosso (8) & Fund.UFMT & 0,00 & $0, \infty$ & 0,00 & $0, \infty$ & 5944693,00 & 0,00 & 0,00 & 0,00 & 0,0 & 0,00 & $5.944 .690,0$ \\
\hline 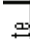 & Sergipe(8) & Fund.UFSE & 0,00 & 0,0 & 0,00 & 0,0 & 0,00 & 0,00 & $4.150 .000,00$ & $5.100 .000,00$ & $11.359 .560,00$ & $8.918572,00$ & $29.528 .137,0$ \\
\hline 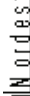 & Bio Grande do Narte (8) & Fund.JFRN & 0,00 & 0,0 & 0,00 & $0, \infty$ & $7025.037,00$ & $6.800 .000,00$ & 0,00 & $7.000 .000,00$ & $8.357 .000,00$ & $9.009091,00$ & $39.172 .606,0$ \\
\hline$=$ & Aпяра́( (8) & Fund.Uni & $5.000 .000,00$ & 0,0 & 0,00 & 0,0 & 0,00 & 0,00 & 0,00 & $8.900 .000,00$ & 90148870,00 & $0,0,00$ & $22.914 . B 7 B, W$ \\
\hline$\infty$ & Roraima (8) & FUFRR & 0,00 & 0,0 & 0,00 & 0,0 & 0,00 & 0,00 & $7.400 .000,00$ & 0,00 & 0,0 & $10.000000,00$ & $17,4 \infty, 0 \infty, \infty$ \\
\hline 壱 & Acre (8) & F.Fed.Acre & 0,00 & 0,0 & 0,00 & 0,0 & 0,00 & $3.459 .200,00$ & $3500.000,00$ & 0,00 & 0,0 & 0,00 & $6.909 .20,0$ \\
\hline$=$ & Tocantis (8) & FUFTO & 0,00 & 0,0 & 0,00 & $0, \infty$ & 0,00 & 0,00 & 9250000,00 & 0,00 & 0,0 & 0,00 & $9.250 .000,0$ \\
\hline & Bondônia(B) & Fund.UFRO & 0,00 & 0,0 & 0,00 & 0,0 & $13203.556,00$ & $\begin{array}{r}0,00 \\
\end{array}$ & 0,00 & 0,00 & 0,0 & 0,00 & $13.209 .56,0$ \\
\hline N & Amazunas (8) & Fund. & $4.000 .000,00$ & $4.000 .000,00$ & $6.126 .640,00$ & $8.30 .000,00$ & 0,00 & 6.862.000,00 & $12.700 .000,00$ & $16.900 .000,00$ & 0,0 & 0,00 & $56.668 .640,00$ \\
\hline NE & Alagoas (9) & UFAL & $2.200 .000,00$ & 0,00 & 0,00 & $0, \infty$ & 0,00 & 0,00 & 0,00 & $4.400 .000,00$ & 0,0 & 0,00 & $6.600,00$, \\
\hline SE & Espírito Santo (10) & UFES & 0,00 & $4.500 .000,00$ & 3879040,00 & & $2877,501,00$ & $4.869 .200,00$ & $4.250 .000,00$ & $11.200 .000,00$ & $7,698.381,00$ & 0,00 & $39.274,12, \infty$ \\
\hline NE & Piaú (10) & Fund. & 0,00 & 0,0 & 0,00 & $0, \infty$ & 0,00 & 0,00 & 0,00 & 0,00 & $0, \infty$ & 0,00 & 0,0 \\
\hline NE & Paraíba(12) & UFPB & 0,00 & $0, \infty$ & $6.465 .360,00$ & 0,0 & $5,301.254,00$ & 0,00 & 0,00 & 0,00 & 0,0 & 0,00 & $11.646 .614,0$ \\
\hline SE & Santa Catarina (16) & UF SC & 0,00 & 0,0 & 0,00 & $0, \infty$ & 0,00 & 0,00 & 5525000,00 & 0,00 & $27.042 .357,00$ & 0,00 & $33.367,357,00$ \\
\hline & - & & 16.000 .00000 & 15.600 .0000 & 19.121 .040000 & $18.550,000,0$ & $40,824,584,00$ & 38.0000000 & 56.851 .90000 & 60.0000000 & $92.652 .600,0$ & $46,301266,00$ & (1) \\
\hline
\end{tabular}


Primeiramente, observa-se a constância ininterrupta com que a UnB mantém-se agraciada com emendas da sua bancada de sua Unidade Federativa ao longo de nove anos, perfazendo um total de $\mathrm{R} \$ 77.418 .967,00$.

Observe-se que no ano de 2009, a UnB não obteve emenda de bancada, como conseqüência de um momento de crise em 2008, quando a Instituição voltou-se para si mesma em função de questões internas. A emenda de 2009, (R\$ 2.300.000) foi um somatório de várias emendas individuais para construção de um espaço dentro do campus para os técnicos administrativos. Essa foi uma iniciativa da Fasubra.

A primeira metade do período estudado (2000-2004) demonstra que houve uma dispersão com relação à obtenção de recurso orçamentário, pelas IFES, que possuem bancadas iguais ou próximas à Bancada do DF.

Já no intervalo que compreende os anos de 2005 até 2009, observamos um aumento significativo de inclusão de emendas de bancada para suas respectivas universidades localizadas em seus estados de origem.

Uma possível explicação para esse evento, talvez seja o fato de que os reitores dessas IFES tenham percebido esse mecanismo de atuação junto ao C.N. para obtenção de recursos orçamentários junto à União.

Atente-se também, para certa continuidade / constância que algumas IFES apresentam a partir do meio da tabela para o final (2005-2009), podendo ser esta uma tendência que talvez tenha vindo para ficar. 


\section{Capítulo 7- UnB X IFES COM BANCADAS MAIORES}

Ao analisarmos a Universidade de Santa Catarina (UFSC) que é do mesmo porte da UnB, possuindo uma bancada que é dobro da Bancada do DF, constatamos que não há uma relação forte entre a bancada e sua universidade, pois o montante alocado na emenda orçamentária de 2008, parte dela destina-se à implantação da Universidade Federal da Mesorregião do Mercosul (UFMM) - campus Chapecó.

Constatamos também que a Universidade Federal de Goiás (UFGO), de porte equivalente ao da UnB, apesar de possuir uma bancada de 17 (dezessete) deputados federais, somente a partir de 2007, ou seja, nos 3 (três) últimos anos analisados da nossa série conseguiu alocar emendas no orçamento da União.

Ao compararmos a UnB com uma universidade de cada região, que possuem bancadas maiores que a do DF no $\mathrm{CN}$ e que possuam orçamentos similares junto à União (LOA-2009).

Tab. 4 - Comparativo entre UnB e IFES com bancadas maiores e orçamentos aproximados (Valores em R \$1.000)

\begin{tabular}{|l|l|l|l|l|l|l|l|l|l|r|r|}
\hline \begin{tabular}{|l|l|l|l|l|l|l|l|} 
IFES \\
LOA
\end{tabular} & 2000 & 2001 & 2002 & 2003 & 2004 & 2005 & 2006 & 2007 & 2008 & 2009 & \\
\hline UNB & 10.000 & & & 10.000 & $7.392,54$ & 51.000 & $8.926,90$ & 10.300 & $13.540,72$ & & 111.160 \\
\hline UFSC & & & & & & & 5.525 & & $27.842,35$ & & 33.367 \\
\hline UFMG & & & & & & & & & & & 0 \\
\hline UFG0 & & & & & & & & 15.000 & $11.238,89$ & $17.563,60$ & 43.802 \\
\hline UFBA & 16.000 & 14.000 & $11.560,40$ & 10.000 & 8.250 & 50.000 & $16.684,50$ & 17.800 & $23.501,10$ & 9.500 & 177.296 \\
\hline
\end{tabular}

São elas: Na região Sul a Universidade Federal de Santa Catarina (UFSC) bancada com 16 deputados e 3 senadores, no Sudeste a Universidade Federal de Minas Gerais (UFMG) bancada com 53 deputados e 3 senadores, no Centro-Oeste a Universidade Federal de Goiás (UFGO) bancada com 17 deputados e 3 senadores, no Nordeste a Universidade Federal da Bahia (UFBA) bancada com 39 deputados e 3 senadores e na região Norte a Universidade Federal do Pará (UFPA) bancada com 17 deputados e 3 senadores num total de 33 parlamentares. 
Neste levantamento, o que nos chama a atenção é a constância com que a UFBA consegue também alocar emendas junto à sua bancada, tal qual a UnB. Mas, devemos lembrar que a UFBA tem uma bancada de 39parlamentares, ou seja, quase cinco vezes o tamanho da bancada à disposição da UnB.

As universidades do Sul e do Centro-Oeste descobriram esta modalidade somente nos últimos quatro anos, e a do Norte e Sudeste ainda não viabilizaram esta possibilidade de mais recursos no seu orçamento.

Infelizmente, este é um caminho que mistura burocracia e política, ainda desconhecido por uma parcela das IFES, pouco utilizado por algumas e otimizado pela minoria, entre elas, a UnB.

Nem sempre estas emendas se traduzem em recursos na sua totalidade, e na maioria das vezes só parcialmente. Para liberá-las há de se fazer um esforço político junto ao Poder Executivo utilizando-se mais uma vez a força da bancada. Mas, se a emendas não chegarem nem a serem produzidas, aí então o resultado será nulo, com certeza. 


\section{CONCLUSÃO}

Em função do rodízio anual de coordenadores de bancada, relatores geral/setoriais, líderes partidários, presidentes de comissões, novos assessores, etc, esse processo implica um relacionamento diferenciado entre as instituições $\mathrm{UnB}$ e o $\mathrm{CN}$. A cada ano, para que a UnB obtenha sucesso em seu relacionamento com o CN, se faz necessário apresentar aos novos líderes os projetos desenvolvidos pela Instituição junto à comunidade, a fim de que essas mesmas lideranças passem a conhecer e a compreender (defender) o trabalho desenvolvido pela Universidade.

Isso tem se dado em encontros formais ou informais, utilizando diversas estratégias de aproximação, até que se concretizasse a alocação de emendas pelos parlamentares, demonstrando que a estratégia adotada de construir canais de aproximação entre a UnB e o C.N. foi profícua.

Este trabalho desenvolvido pela UnB ao longo destes 12 anos, é um trabalho com consistência, que apresentou resultados favoráveis à Instituição para que ela possa desenvolver seus projetos e atender a comunidade do DF e região.

Conforme dados levantados junto as LOAs que estão disponibilizados no site da CD e SF (Orçamento Brasil) verificamos que outras IFES da amostra estudada, tem utilizado desta estratégia, de uma forma não tão constante e sistemática quanto a UnB.

Constatamos também, que um grupo de universidades federais nos últimos cinco anos tem procurado trabalhar junto às suas bancadas estaduais (Deputados e Senadores), com a finalidade de obter recursos que complemente o seu orçamento anual.

É importante salientar que a ANDIFES também utiliza mecanismos de aproximação com os parlamentares obtendo resultados positivos junto à $\mathrm{CE}$, todavia os dados demonstraram o bom desempenho da UnB quando comparadas.

Esse trabalho de influência da UnB junto ao C.N. tem sido realizado de forma institucional, sem troca de favores de espécie alguma, independentemente das várias 
administrações que transcorreram ao longo do período estudado. Essa abordagem é parte constitutiva do regime democrático, o acompanhamento de assuntos pertinentes à universidade pública contribui para o seu aperfeiçoamento.

A abordagem (lobby público e institucional) ao parlamento brasileiro, acontece por atuação do próprio governo, pois quase todas as unidades do poder Executivo têm suas próprias assessorias parlamentares que pressionam fortemente. Tanto o poder Judiciário quanto o Ministério Público se fazem presentes também com as suas assessorias.

Além disso, há a influência (lobby do setor privado) na educação, de ONGs , de governos estrangeiros e também pressão de grupos (lobby classista) das entidades patronais (CNA, CNI, etc) e entidades dos trabalhadores (CUT, Força Sindical, Contag, etc)

As emendas obtidas coletivamente pela UnB ao longo desta série histórica (20002009) foram frutos de um trabalho suprapartidário, e passaram por várias legislaturas independentemente do resultado que cada eleição propicia na Bancada do DF.

Esse processo de conseguir emendas fossem elas individuais ou coletivas (de bancada) em um primeiro momento eram quase que exclusividade da UnB, mas atualmente várias IFES tem utilizado deste expediente.

Por ser uma pesquisa exploratória que tinha como objetivo estudar a relação da UnB com o $\mathrm{CN}$, especialmente em atividades que visavam influenciar decisões que seriam tomadas pelos parlamentares no uso de recursos orçamentários, podemos concluir que pela análise dos dados constantes nas LOAs, o trabalho da UnB é de grande eficiência se comparado com outras IFES analisadas. Constata-se que a Universidade trabalhando junto à Bancada do DF consegue buscar recursos os quais serão empregados nas atividades de investimento em ensino, pesquisa e extensão assim como também em custeio.

Projetos como reforma e modernização da infra-estrutura física da UnB foram viabilizados, graças à sensibilidade da Bancada do DF para com a Instituição, ao longo dos anos pesquisados. 
Torna-se importante observar que a inclusão de emendas nos orçamentos anuais, não é garantia de que serão liberados para a Instituição. Ressalte-se que a UnB é uma das IFES das quais mais sucessos tem obtido nessa atividade. Não é a única, todavia é uma das que tem envidado esforços para que sua atividade de expansão se concretize.

Essa parceria entre a UnB e a Bancada do DF traz vantagens para os dois lados: A UnB torna-se presente na comunidade do DF e região, ocupando novos espaços viabilizados pelos recursos orçamentários e os parlamentares, independentemente de ideologias, passam a gozar de prestígio junto ao seu eleitorado, por ajudar a levar a universidade pública a suas regiões.

Pelos resultados obtidos que se traduzem em emendas conseguidas, ao longo destes anos, podemos concluir que Universidade de Brasília detém uma imagem respeitada diante da Bancada e também da sociedade do DF. O trabalho da UnB não tratou somente de trazer recursos, mas de influenciar positivamente o parlamentar no sentido de aproximarmos a Instituição, uma das mais importantes universidades deste país, ao Congresso Nacional. 


\section{BIBLIOGRAFIA}

ARAGÃO, Murillo de. Grupos de pressão no Congresso Nacional: como a sociedade pode defender licitamente seus direitos no Poder Legislativo. São Paulo: Maltese, 1994.

BOBBIO, Norberto, MATTEUCCI, Nicola \& PASQUINO, Gianfranco. Dicionário de Política. Brasília: Ed. UnB. 2007. 13ª Ed.

BRASIL. Constituição da República Federativa do Brasil, de 1988.

BRASIL. Orçamento Brasil www.camara.gov.br e www.senado.gov.br.

CÂMARA DOS DEPUTADOS. Regimento Interno da Câmara dos Deputados, de 2006.

GRAZIANO, Luigi. O lobby e o interesse público. In: Revista Brasileira de Ciências Sociais. vol. 12 n. 35 São Paulo Feb. 1997.

MACIEL, Marco. Projeto de Lei do Senado n 203, de 1989.

MORHY, Lauro. (org.). Plano de expansão da Universidade de Brasília: Campus UnB Planaltina, Campus UnB Ceilândia/Taguatinga, Campus Gama. Brasília, 2005

MORHY, Lauro. (org.). Universidade em Questão. Brasília. UnB, 2003.

OLIVEIRA, Andrea Cristina de Jesus. Lobby e representação de interesses: lobistas e seu impacto sobre a representação de interesses no Brasil. Campinas: Unicamp. 2004. (Tese de Doutorado defendida no Instituto de Filosofia e Ciências Humanas). 